\title{
Preventing Dust Collection Transforming Student Affairs Strategic Planning into Tangible Results
}

\author{
"Deep organizational change" was the goal of the University of Michigan's Division of \\ Student Affairs in 2001 when it began an interactive and reflective planning process using \\ research. The dust has not "settled" since then, and this case study highlights how a \\ process that invests in staff can transform planning into action.
}

by Simone Himbeault Taylor and Malinda M. Matney

Simone Himbeault Taylor is associate vice
president for student affairs at the University
of Michigan. She is also an adjunct assistant
professor in the Center for the Study of
Higher and Postsecondary Education.
Malinda M. Matney is senior research
associate, coordinating research and
assessment initiatives for the Division of
Student Affairs at the University of Michigan.
She is also a lecturer in the Center for the
Study of Higher and Postsecondary Education.

Simone Himbeault Taylor is associate vice president for student affairs at the University of Michigan. She is also an adjunct assistant professor in the Center for the Study of Higher and Postsecondary Education.

Malinda M. Matney is senior research associate, coordinating research and assessment initiatives for the Division of Student Affairs at the University of Michigan Study of Higher and Postsecondary Education

\section{Introduction}

The University of Michigan Division of Student Affairs is engaged in an iterative strategic planning process. One critical component of this process has been the creation and implementation of long-range division-wide goals meant to last from five to seven years. This "strategic journey," begun in 2000 , continues to evolve, uniting the guiding framework of strategic planning steps with a reflective process that includes a prominent assessment component employed within each step and a group process approach that supports individual growth in the service of organizational change. This model has advanced the division's strategic direction, allowing divisional leadership to manage from an informed perspective and shape a shared vision. Ongoing assessment efforts have contributed to establishing and defining division-wide goals, using research findings to inform the goal formulation steps of the strategic process.

The University of Michigan is a highly selective public research university located in Ann Arbor, Michigan. It is primarily a residential campus with approximately 40,000 students in 19 schools and colleges 23,000 undergraduates, with the balance in graduate and professional programs). The Division of Student Affairs, like similar divisions at other institutions, encompasses a comprehensive array of units 
and functions, including numerous partnerships with faculty. As is the case in many decentralized institutions, most divisional units at Michigan have engaged previously in independent strategic planning to create and support their own missions.

\section{A process that invests in staff can transform planning into action, leading to deep organizational change.}

The new model developed by the Division of Student Affairs sought to identify common threads to complement, not replace, unit efforts. We determined that divisional units are bound together by a common mission of student learning and development of the whole student, along with a commitment to shaping an environment conducive to effective learning in a diverse campus community. As a result, a group of divisional leaders engaged in a strategic planning process with a commitment to student learning as the focus of their work. In this article, we describe a model for conducting systematic divisional planning; demonstrate an interactive and reflective process, using research; and highlight how a process that invests in staff can transform planning into action, leading to deep organizational change.

\section{Strategic Planning Process}

Beginning in 2000, the Division of Student Affairs launched a major strategic planning process with the purpose of effecting deep organizational change. "Deep change" refers to Quinn's (1996, p. 219) concept of a journey of personal change that leads to organizational change, whereby the organization becomes one that has vision, takes risks, and creates excellence. The ultimate purpose of creating deep change is to optimize the division's contribution to student learning and development. One way this is achieved is by developing a shared understanding that theory and research inform practice and that this grounded orientation elevates practice from a simple set of activities to interventions of purpose (figure 1).

Drawing on the strategic planning literature, the division employed a modified Goodstein, Nolan, and Pfeiffer structure (1993). This model fit well with the deep change concepts we sought to employ and included a strong belief that empowerment of individuals is key to success. Using such a systematic and deliberate model should in no way suggest that each step was approached with a clear and understood end in mind. In Quinn's framework, we sought to "build the bridge as we walked on it" (1996, p. 83). Bridge building requires logical, orderly

Figure 1 Theory and Research Inform Practice

Theory/Research

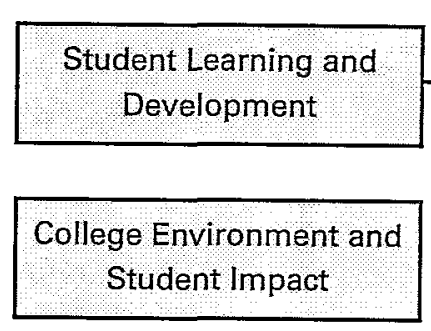

Organizational, Best

Practice, Stewardship

Functional/Content Based
Areas Informed by Theory/Research

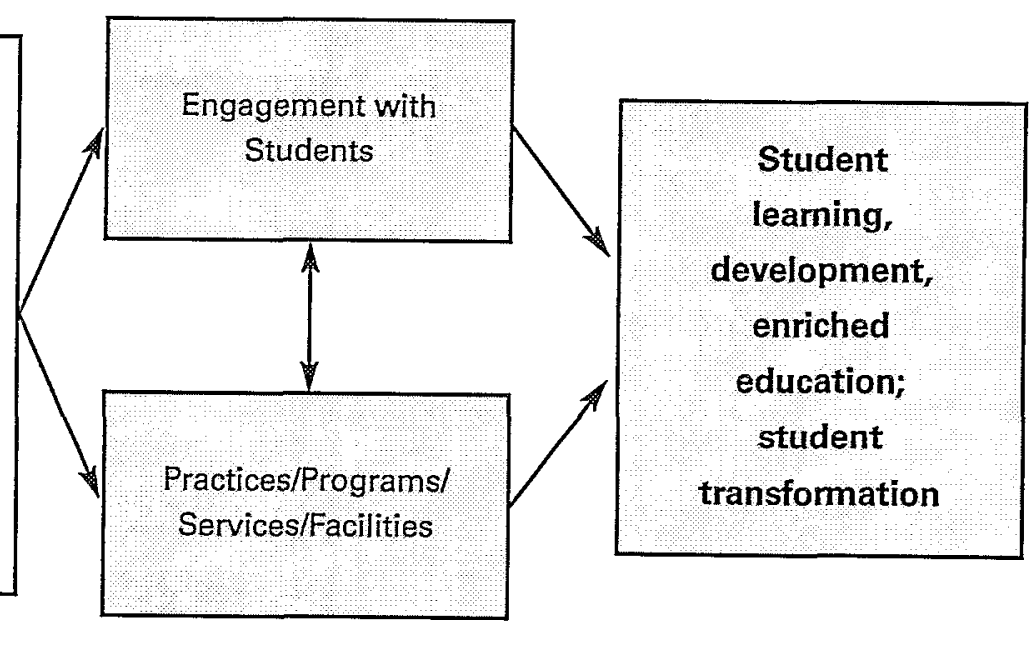




\section{Preventing Dust Collection: Transforming Student Affairs Strategic Planning into Tangible Results}

steps to ensure stability. We needed a blueprint in hand and the critical support posts installed to provide the structure before we could build the expanse. Enough trust in the process design was needed to risk moving forward even as we tested and modified ideas. Goodstein, Nolan, and Pfeiffer (1993) offered an initial structure we could rely on to determine where the division was going (values scan, mission formulation), survey internal and external environments (strategic business modeling), establish the goals that would actualize the mission (integrating action plan), and bring the goals to life (implementation).

The division applied a reflective approach to each structural step in the Goodstein, Nolan, and Pfeiffer (1993) framework that intentionally considered the current literature, engaged in assessment efforts, validated findings, and communicated direction. Borrowing from the Strange and King (1990) model, a graphic depiction of this reflective strategic planning model is presented in figure 2.

\section{Planning the Plan, Values Scan, and Mission Formulation}

To execute a meaningful strategic planning process, it was necessary to assemble a team with enough power to lead a major change effort, a group Kotter (1996, p. 51) labels a "guiding coalition." A senior administrative team "planned the plan" and regularly brought together 45 unit heads and major supervisors from the 25 organizations in the division. Their charge was to work actively to determine organizational values, revise the mission, and develop a set of shared principles for working together. An approach with concrete guidelines informed the process, ensured that unit staff (through their unit heads) were engaged, and helped the leadership move forward on important divisional decision points. While the outcome of this process was variable (which provided meaningful information about unit readiness for division-wide engagement), it resulted in the creation of building blocks for future strategic goal work.
Figure 2 Reflective Strategic Planning Process

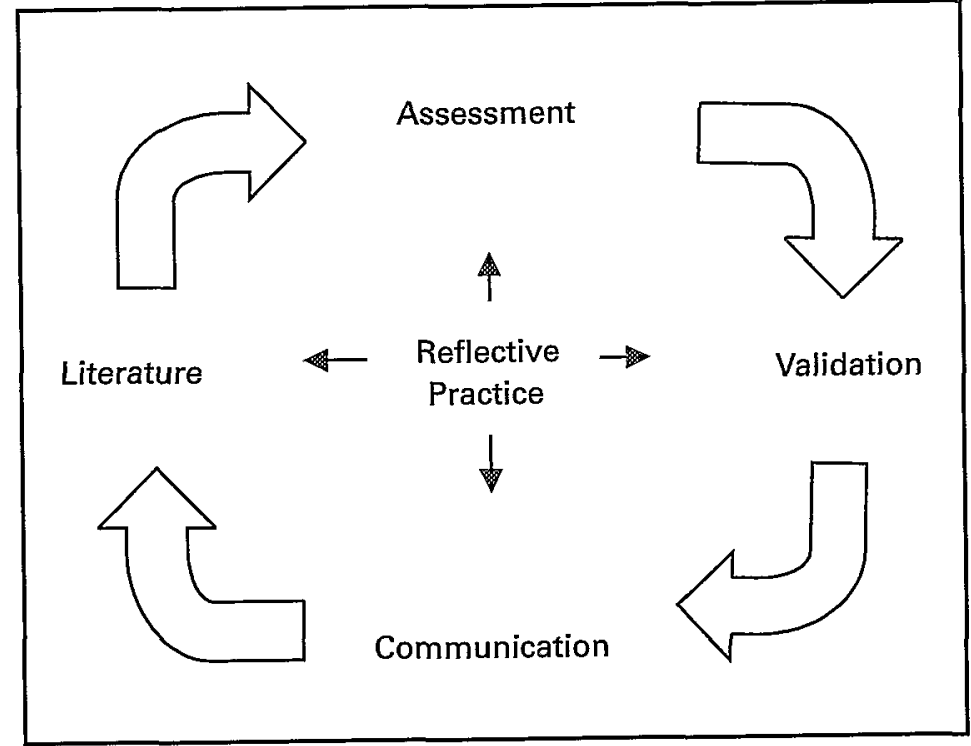

\section{Strategic Business Model}

With the essential building blocks in place (mission, organizational values, and shared principles), the division was prepared to engage substantively in the strategic business modeling step (figure 3 ). This translated to developing a specific goal-setting subplan that included establishing goal parameters and engaging in substantive data input, analysis, and validation to create the goals.

Defining goal parameters was an exercise in determining the criteria that a "good" goal would need to satisfy. Examples included assessing whether the goal was achievable and clearly articulated and whether the goal supported and enhanced institutional goals and fit with the division's values and mission.

Figure 3 Strategic Business Model

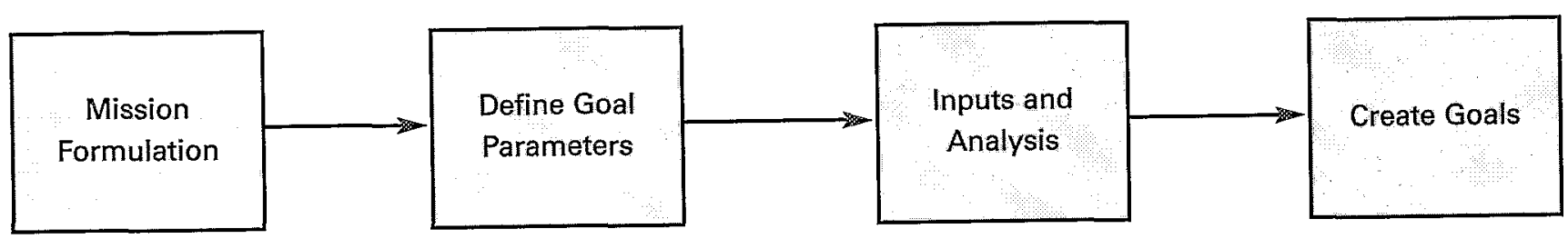


The ultimate aim was to derive and implement a set of key division-wide goals (distinct from unit-level efforts). Optimally, these division-wide goals would address the most compelling concerns and provide the impetus for developing cohesive, integrated, and interdisciplinary educational interventions in the division's programs, services, and facilities. To identify these goals, the first of several assessment initiatives was launched (inputs and analysis).

\section{Goal identification and validation process.} Students, faculty, and staff were asked to offer feedback about what issues were on students' minds and what areas of focus should be included in the division's goals. While the focus of this article precludes engaging in extensive detail regarding specific research methodology and findings, the process followed accepted protocols for focus group methodology and analysis found in the qualitative research literature (Glaser and Strauss 1967; Kirk and Miller 1986; Lin 1998; Yin 1994). An analysis of strong common themes across groups then generated an aggregate set of major themes cutting across all groups. A report developed by a full-time Division of Student Affairs research staff member and her student staff was used by the guiding coalition to inform the next step, the shaping of straiegic goal areas.

Engaging divisional leaders to conduct the focus groups resulted in important process outcomes associated with the reflective strategic planning process model (figure 2). Rather than creating a situation in which positional leaders could discount the research findings as counterintuitive to their work, the leaders were able to make direct connections between the findings from the aggregated information and the focus groups or interviews they themselves conducted. This started the reflective process in a tangible manner and facilitated the communication of findings.

The results of this strategic planning data gathering effort were viewed and applied in a variety of ways. The information was combined with findings from several surveys of and about university students as well as with documents from national organizations such as the Association of College Personnel Administrators, the National Association of Student Personnel Administrators, and the National Survey of Student Engagement administered by Indiana University. These sources represent a return to the "literature" component of the reflective strategic planning process model. in many ways, the literature, as well as the leadership's professional judgment, confirmed the results of the focus group feedback.

The most notable outcome was the creation of long-range goals for the Division of Student Affairs. Goals were analyzed in terms of dominant areas (those that directly served the division's mission) and those that were in service of the dominant areas. As a final assessment component in the goal-setting process, we invited students, faculty, and staff to offer narrative comments regarding the proposed goals through a Web site. The leadership considered all comments as it revised the goal language prior to establishing the final goals.

The division was now poised to implement its goals, confident that the goals were grounded in current research and institutional culture and that a critical mass of staff members were prepared to advance the division's mission. The goals reflected areas for intentional collective emphasis. It was understood that these goals were so fundamental to the essential work of the division that an array of efforts already existed to support their implementation.

\section{On the Journey of Deep Change}

Because the Goodstein, Nolan, and Pfeiffer (1993) model is complete at implementation, we used the reflective strategic planning process model shown in figure 2 (literature, assessment, validation, communication) and our own ongoing reflection about lessons learned during the goal-setting effort to guide the implementation process. Returning to the literature, we were reminded that individual understanding translates to transforming selves and organizations (Hackman 2002; Kegan and Lahey 2001; Quinn 1996) and that all "frames" of the organization must be employed in managing change (structural, human resource, political, and symbolic frames, as described by Bolman and Deal [1997]).

Managing resistance. Any successful process needs to engage others actively: the engagement of divisional members shapes both the process and the outcome. One outcome sought was the ongoing transformation in staff that would both represent change and create more change. In any large organization levels of commitment to and comfort with organizational change will vary greatly by individual. While a critical mass committed to change existed from the start, leaders varied in their support of-or opposition to-a more centralized divisional vision. Cohen and March (1974, p. 62) speak to the rules of leadership in 
an "organized anarchy:" one rule addresses the importance of facilitating oppositional participation. We believed that it was critical to our success to have all key organizational voices represented. Another helpful rule was to provide "garbage cans," alternative mechanisms outside the planning process for important issues not immediately relevant to planning that might distract from moving forward with the change agenda. Spending time and not overloading the system were other helpful rules derived from Cohen and March.

"Interruptions" as opportunities. During this process, divisional and institutional work continued with its own surprises and challenges. From student protests on timely issues, to 9/11, SARS, the East Coast black out, the tsunami, alcohol and hazing concerns, the University of Michigan Supreme Court cases, and budget crises, many international and local issues competed for our attention. Sometimes this contributed to the continuing tension inherent in balancing immediate crises with long-range planning. Conflicts needed to be managed so that immediate issues could be addressed while not minimizing the importance of the organization's long-term vision or providing permission for detours or barriers to the division's committed direction. Indeed, many crises called on staff to commit to our mission and live our organizational values, and there were many opportunities to apply our reflective model.

The introduction of outside consultants also created an important, if not initially envisioned, means of advancing our strategic planning. To address staff overload, consultants were hired midway through the process to assist in managing the goal-setting component of the model. While the consultants proved helpful to senior leadership in managing the bigger picture, the positional leaders found the introduction of outsiders disruptive and rebuffed their efforts with vigor. The positional leadership group was vocal and the senior leadership listened and subsequently dismissed the consultants. This act was pivotal in achieving enhanced trust, credibility, and commitment with the broader leadership. From that point on, a bonding occurred that allowed the internal group process to progress much more smoothly.

While not as tidy as a controlled experiment where one can directly attribute change to a specific intervention, clearly the process of engaging in an intentional, iterative, reflective, and participative planning effort had an impact both within and beyond goal setting.

\section{Goal Implementation}

Similar to the initiation of the goal-setting process, the first step in implementation was to plan the plan. For this, a subgroup of 10 positional leaders was selected to propose a goal implementation method. This subgroup delineated and managed the steps from goal identification to implementation. Drawing symbolically on a metaphor introduced by the vice president of student affairs that there are many legitimate, unique ways to "get to 9 " (for example, $4+5,3 \times 3,10-1)$ and that the most important task for our division was to have a shared notion of what " 9 " is, the subgroup recommended developing "9 statements" for each goal. Each " 9 statement" was comprised of 15-20 statements that the broader leadership group reviewed, altered, and validated, paving the way for the next assessment effort.

\section{The process of engaging in an intentional, iterative, reflective, and participative planning effort had an impact both within and beyond goal setting.}

The subgroup proposed a two-phase model for goal implementation. In the systems management world, the two phases would be framed as "as is" and "should be," with the idea that we need to learn where we are in order to know where we want to go. In Phase 1 (the "as is" analysis), a standardized method (survey) for gathering key information directly from units on all existing goal-related efforts was developed and executed. It was expected that the resulting gap analysis report would inform Phase 2, ostensibly the "fill-in-the-gaps" implementation of the goal initiative. At this point the broader leadership group demonstrated signs of strategic planning fatigue. In response, the decision was made to locate the goal work within a subgroup and to encourage more links directly with the units themselves. The larger group greeted this shift to a smaller, cross-divisional group positively. This group wanted to continue movement toward our goals and desired ongoing transparency and involvement in the validation process, but was ready to be released from making every decision collectively. This may have been an indicator of growing trust. 
The subgroup symbolically named itself the N.I.N.E. group, serving as an acronym for "New Information, Not Evaluation." This label sent an important message throughout the division that the steps toward goal implementation would be non-threatening and non-judgmental. The purpose was simply to determine the current situation relating to divisional goals through surveys. This is one example of how sensitivity to the organization's political framework (as proposed by Bolman and Deal [1997]) was addressed.

\section{Process can represent an outcome in and of itself.}

Note that this process took a full year of effort. Far from this being perceived as negative, it is another important example of how process can represent an outcome in and of itself. The process of completing the survey-because it was directly grounded in the goals and concrete manifestations of delivering on the goalscaused staff to gain a deeper personal understanding of their individual goals and to engage in active reflection on how their unit might contribute to these division-wide priorities. The assessment also served as a means of communication and an impetus for triggering the reflective process. Like an upward helix, we returned to issues regularly, and with each iteration, we revisited the issue at a higher plane (figure 4).

The result was not simply data gathering but also learning advancement and goal commitment at deeper levels within units. The report was placed on the divisional Web site so that all staff could access the study findings.

Application of results. The survey revealed that many goal-related initiatives were already being executed, leading to the conclusion that it was not the absence of intentional goal-related efforts but the absence of data on the impact of existing initiatives that was the fundamental gap requiring attention. While there was room for introducing new initiatives and seeking economies of scale and synergies from existing efforts, this was clearly not the chief issue. Furthermore, while there was data gathering regarding specific events, few measures went beyond attendance figures and satisfaction surveys (output) to define the effect of those efforts (outcomes).

The most unexpected finding related to goal achievement was not finding a gap in the "what" of our work but in the "so what" of our efforts. The large number of initiatives
Figure 4 Helix of Iterative Strategic Goal Process

\section{Outcomes}

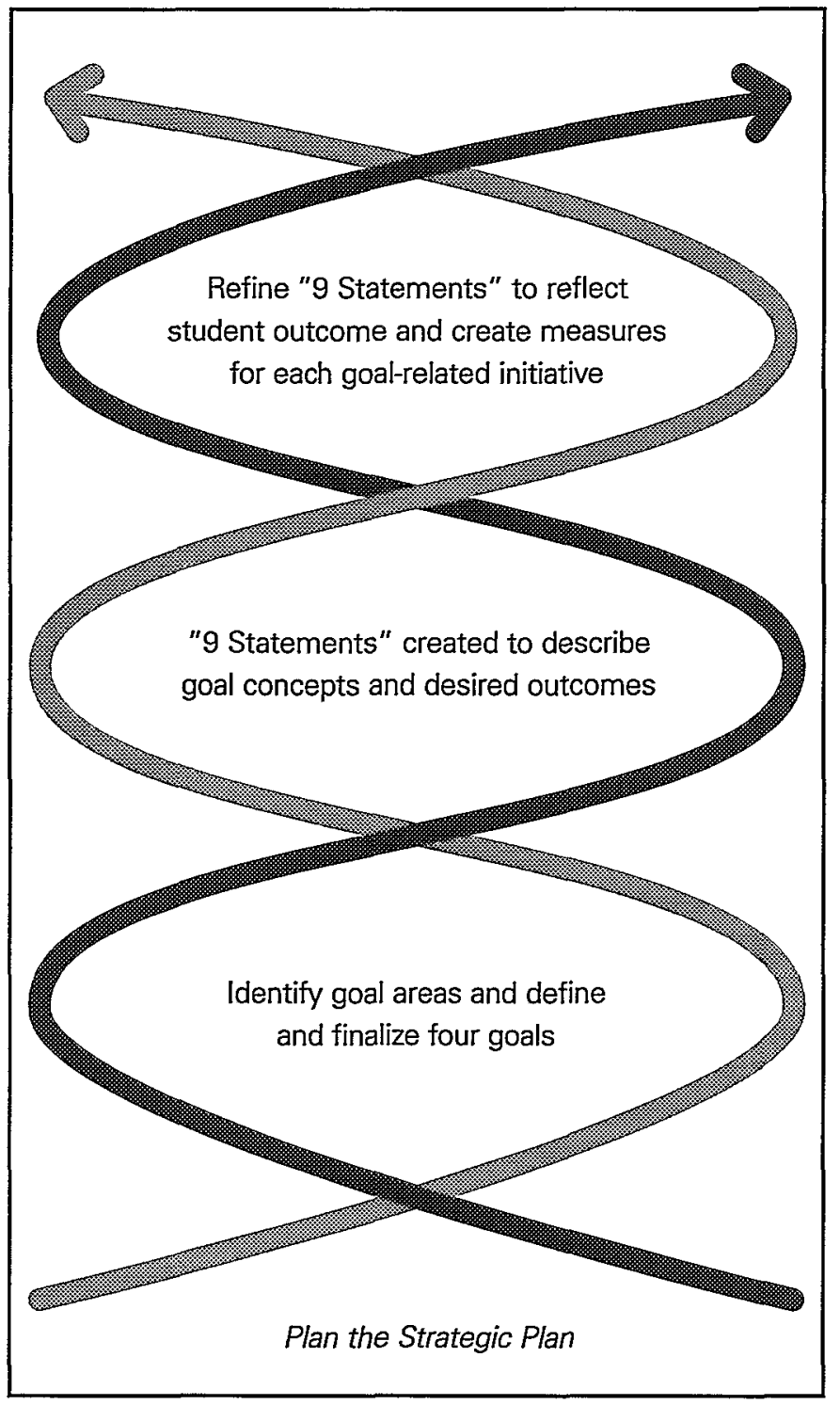

coupled with minimal substantive assessment pointed the way for Phase 2 of goal implementation. Based on the research findings, the broader leadership validated that future emphasis needed to be less on new initiative creation and more on assessment to discover the ways in which outcomes were being met. Three unique sets of work were identified for Phase 2: staff training on key issues of interest, development of an infrastructure to encourage cross-functional initiatives, and measurement of student outcomes. 


\section{Lessons Learned}

Our experience offers valuable lessons both for researchers and organizational leaders:

- The strategic process is not an event, but an ongoing journey. Through a strategic process situated in a structural foundation and complemented by the iterative cycle embedded in the reflective strategic planning process model introduced in this article as a model of choice (figure 2) we witnessed the ongoing personal growth of divisional staff and the incremental achievement of organizational change. With each iteration, the organization continues to work on many of the same issues (i.e., goals) at an increasingly elevated and refined position, as illustrated in the helix diagram (figure 4). There is no "dust collection" in such a dynamic model. Building trust, gathering feedback to send the message that we are serious about obtaining full voice, creating transparent data collection, repeating data collection efforts at numerous points, and trusting the process are key lessons for the leadership guiding such a broad effort and for the staff engaged to play an active role in its execution.

- Evidence of progress reveals itself in tangible and intangible ways. Clear advancement toward our desired outcome was apparent despite the fact that the reality of strategic planning differs greatly from the orderliness of most models. Evidence that palpable change was occurring in divisional staff and in our approach to our work was apparent during the first three years of the journey. For example, annual retreat evaluations asked leaders to position themselves on a change quadrant: Denial, Resistance, Exploration, or Commitment. In the first year, all respondents clustered heavily between Resistance and Exploration. By the third year, there was observable drift out of Resistance and into Exploration and Commitment. Another example represents change using Bolman and Deal's (1997) symbolic frame: the adoption of shared language. Leaders and staff regularly employed goal language in discussions. "Code talk" was used naturally, such as the "getting to 9" language. We also saw newly formed division-wide committees embedding relevant goals within their own charges.
- Interrelated processes provide synergy. The institution's mission, values, and goals helped shape the division's mission, principles, values, and goals. Divisional goals represent one major element of an even broader strategic planning effort that includes a research agenda to allow management from an informed perspective, strategic data planning, staff professional development, academic linkages, and resource stewardship. These pieces represent the multiple strands that travel separately and sometimes intertwine to move the overall strategic direction forward. Each of these components may be managed through the reflective strategic planning process model presented.

- How a question is framed influences the answer. Kotter $(1996$, p. 35) identifies "establishing a sense of urgency" as the first of eight stages for leading change. Even if the motivation behind change is continuous improvement, there is a strong dynamic at play to fix only what is broken. Despite being driven toward excellence, an external motivator helps to effect change-something that needs to be fixed, or perhaps fiscal pressures. For administrators guiding a change process, this means carefully considering how questions are posed and how findings might be framed.

- Expect and understand staff resistance and fatigue. Conceptual understanding does not mean complete trust or investment in a process. Using a guiding coalition of 45 (and eventually 60 ) unit leaders provided a critical mass to guide the organization's new direction. Continuous communication of the message throughout the organization is time- and resource-intensive but worth the return. The good news about staff resistance is that it may mean that group members care about and are protective of the organization. This can be leveraged on behalf of the organization. In turn, with an ongoing process without a natural end, it is important to be watchful for strategic fatigue. Change is slow and tiring. Providing the means for staff to enter and leave the process allows for greater sustainability over time even though it might mean sacrificing critical talent in the moment. It is the job of the guardians of the process to try to remain several steps ahead of the process, to be open and flexible as to how new information influences the overall process and its specific steps, to invite others to share guardianship over substantive parts of the process, 
and not to become demoralized by others' fatigue. Reading relevant literature and connecting regularly with others who value the work can provide a necessary and valued boost.

- Assess, document, validate, and communicate. This is vital for qualitative endeavors where communication is key. The data input and analysis involved in setting goals and inventorying initiatives were intensive and sensitive. Students, faculty, and staff needed to feel confident that they were being heard and, when appropriate, that their information would remain confidential. Users of the information needed to feel confident that they were reviewing accurate data. The power for ultimate change was embedded in the voices of those who expressed their views. Validation, in its formal sense and as a strategy for ensuring that voices are not only heard but that appropriate meaning is made of them, is a powerful tool to reinforce what you think you know is true. It allows for participative management, where iterative processes give an opportunity to shape the outcome to those invested in it.

\section{Conclusion}

Any process-from strategic planning to specific individual efforts-is a series of trade-offs, unintended consequences, and serendipity. Staying open and not always being in search of the "right" answer provides for much possibility. There is no dust collection in such a dynamic process; the particles are not permitted to stay in place long enough to settle. While not as tidy as an approach with a delineated beginning and end, this model respects the interconnectedness of multiple processes and acknowledges that an iterative approach allows for the incremental growth and change that opens the road for the next stage of the journey. In the end, the specific content outcomes-such as particular goal identification-might mean far less in the bigger picture than the process that leads to the content. The process for change continues to serve as a deep change intervention. $\boldsymbol{x}$.

\section{References}

Bolman, L. G., and T. E. Deal. 1997. Reframing Organizations: Artistry, Choice, and Leadership. 2nd ed. San Francisco: Jossey-Bass.

Cohen, M. D., and J. G. March. 1974. The Processes of Choice. In ASHE Reader on Organization and Governance in Higher Education, ed. M.W. Peterson, 61-69. 3rd ed. Needham Heights, MA: Ginn, 1986.

Glaser, B. G., and A. L. Strauss. 1967. The Discovery of Grounded Theory: Strategies for Qualitative Research. New York: Aldine.

Goodstein, L. D., T. M. Nolan, and J. W. Pfeiffer. 1993. Applied Strategic Planning: How to Develop a Plan that Really Works. New York: McGraw-Hill.

Hackman, J. R. 2002. Leading Teams: Setting the Stage for Great Performances. Boston: Harvard Business School Press.

Kegan, R., and L. L. Lahey. 2001. How the Way We Talk Can Change the Way We Work: Seven Languages for Transformation. San Francisco: Jossey-Bass.

Kirk, J., and M. L. Miller. 1986. Reliability and Validity in Qualitative Research. Newbury Park, CA: Sage.

Kotter, J. P. 1996. Leading Change. Boston: Harvard Business School Press.

Lin, A. C. 1998. Bridging Positivist and Interpretivist Approaches to Qualitative Methods. Policy Studies Journal 26 (1): 162-80.

Quinn, R. E. 1996. Deep Change: Discovering the Leader Within. San Francisco: Jossey-Bass.

Strange, C. C., and P. M. King. 1990. The Professional Practice of Student Development. In College Student Development: Theory and Practice for the 1990s, ed. D. Creamer, 9-24. Alexandria, VA: American College Personnel Association. Yin, R. K. 1994. Case Study Research: Design and Methods. 2nd ed. Newbury Park: Sage. 


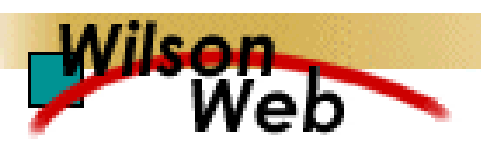

\section{COPYRIGHT INFORMATION}

TITLE: Preventing Dust Collection: Transforming Student Affairs Strategic Planning into Tangible Results

SOURCE: Plann Higher Educ 35 no2 Ja/Mr 2007

WN: 0700101195005

The magazine publisher is the copyright holder of this article and it is reproduced with permission. Further reproduction of this article in violation of the copyright is prohibited.

Copyright 1982-2007 The H.W. Wilson Company. All rights reserved. 